\title{
Peertechz
}

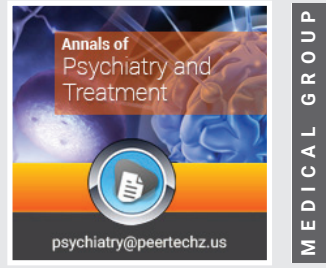

\section{Perrotta Affective Dependence Questionnaire (PAD- 0 ): Clinical framing of the affective-sentimental relational maladaptive model}

Received: 12 April, 2021

Accepted: 09 July, 2021

Published: 10 July, 2021

*Corresponding author: Dr. Giulio Perrotta, Psychologist sp.ing in Strategic Psychotherapy, Forensic Criminologist, Legal Advisor sp.ed SSPL, Researcher, Essayist, Institute for the study of psychotherapies - ISP, Via San Martino della Battaglia no. 31, 00185, Rome, Italy, E-mail: info@giulioperrotta.com ORCID: https://orcid.org/0000-0003-0229-5562 https://www.peertechzpublications.com

\section{Check for updates}

\section{Giulio Perrotta* \\ Psychologist sp.ing in Strategic Psychotherapy, Forensic Criminologist, Legal Advisor sp.ed SSPL, Researcher, Essayist, Institute for the study of psychotherapies - ISP, Via San Martino della Battaglia no. 31, 00185, Rome, Italy}

\begin{abstract}
Starting from the concept of "affective dependence", this work has shown that this nosography cannot be reduced to a categorization in the list of behavioral dependencies, even if it has in common clinical and neurobiological aspects that could be misleading. In fact, the dependent manifestation is nothing more than a symptom that from time to time represents a specific element in various personality disorders, becoming the central focus of dependent personality disorder. The analytical approach must, therefore, be multidimensional, precisely to better understand all aspects of affective dependence and how it colors the manifested disorder from time to time. From affective dependence to personality disorders, in relation to the dynamics of human bonding, to the implications determined by attachment theory, in a framework of diagnostic transversality, to the best possible therapy, always integrated between psychopharmacology and psychotherapy. The Perrotta Affective Dependence Questionnaire (PAD-Q), with 35 items, on a 0-5 scale, aims to study the phenomenon of "affective dependence", defining it instead as a maladaptive model of the affective-sentimental relationship of a couple, which involves the establishment or persistence of a clinically significant bond, lasting at least six months and characterized by a functional impairment of the relational area, the emotional area and the somatic area.
\end{abstract}

\section{Contents of the manuscript}

\section{General introduction: the «affective dependence»}

Generally, when we indicate alterations in the emotionalaffective tone we refer to a whole series of morbid conditions, which have a dysfunctional tone as a common basis; just think of anxiety disorders, among which we find panic, phobias, separation anxiety (at the basis of many psychotic and personality disorders) and generalized anxiety, eating disorders, obsessive-compulsive disorder, post-traumatic stress disorders, somatic syndromes, mood disorders (such as depression, dysthymia, cyclothymia, and suicidal risk), behavioral and substance addictions, bipolar disorder, paraphilic disorder and also a large part of personality disorders. And it is precisely in personality disorders that dysfunctional affectivity becomes a real addiction, often confused even by technicians and therapists (and wrongly treated in psychotherapies) as a new "behavioral addiction" (the so-called "love addiction"), according to one's perception of reality, until it evolves into the largest form: the "personality addiction disorder". Although affective addiction, due to a lack of experimental data, is not included among the mental disorders diagnosed in the DSM-5 (the Diagnostic and Statistical Manual of Mental Disorders), it is erroneously classified among the "New Addiction", new behavioral addictions, including Internet addiction, pathological gambling, sex addiction, sports addiction, compulsive shopping, and work addiction [1].

Reynaud, a decade ago, proposed a diagnostic definition of "love addiction", based on the duration and frequency of perceived suffering, presenting it as: a maladaptive or problematic model of the love relationship that leads to clinically significant deterioration or anguish, as manifested 
by three (or more) of the following criteria (which occur at any time, in the same 12-month period, for the first five criteria): 1) existence of abstinence syndrome due to the absence of the loved one, characterized by significant suffering and compulsive need of the other; 2 ) considerable amount of time spent in this relationship (in reality or in thought); 3) reduction of important social, professional or leisure activities; 4) persistent desire or unsuccessful efforts to reduce or control one's relationship; 5) search for the relationship, despite the existence of problems created by it; 6) existence of attachment difficulties, as manifested by one of the following: a) repeated exalted love relationships without any period of lasting attachment; b) repeated painful love relationships characterised by insecure attachment [2]. However, he too did not consider affective dependence as a symptom of a broader picture, but simply a dependence linked to the affective, sentimental and sexual sphere, reducing it in an excessively simplistic way.

Millon also identified the five subtypes of dependent personality disorder: [3]:

\begin{tabular}{|c|c|c|}
\hline Subtype & Description & Personality Traits \\
\hline Disquieted dependent & Including avoidant features & $\begin{array}{c}\text { Restlessly perturbed; } \\
\text { disconcerted and } \\
\text { fretful; feels dread } \\
\text { and foreboding; } \\
\text { apprehensively vulnerable } \\
\text { to abandonment; lonely } \\
\text { unless near supportive } \\
\text { figures. }\end{array}$ \\
\hline Selfless dependent & Including masochistic features & $\begin{array}{l}\text { Merges with and } \\
\text { immersed into another; } \\
\text { is engulfed, enshrouded, } \\
\text { absorbed, incorporated, } \\
\text { willingly giving up own } \\
\text { identity; becomes one } \\
\text { with or an extension of } \\
\text { another. }\end{array}$ \\
\hline Immature dependent & Variant of "pure" pattern & $\begin{array}{c}\text { Unsophisticated, } \\
\text { half-grown, unversed, } \\
\text { childlike; undeveloped, } \\
\text { inexperienced, gullible, } \\
\text { and unformed; incapable } \\
\text { of assuming adult } \\
\text { responsibilities. }\end{array}$ \\
\hline $\begin{array}{c}\text { Accommodating } \\
\text { dependent }\end{array}$ & Including histrionic features & $\begin{array}{l}\text { Gracious, neighborly, } \\
\text { eager, benevolent, } \\
\text { compliant, obliging, } \\
\text { agreeable; denies } \\
\text { disturbing feelings; } \\
\text { adopts submissive and } \\
\text { inferior role well. }\end{array}$ \\
\hline Ineffectual dependent & Including schizoid features & $\begin{array}{l}\text { Unproductive, gainless, } \\
\text { incompetent, meritless; } \\
\text { seeks untroubled life; } \\
\text { refuses to deal with } \\
\text { difficulties; untroubled by } \\
\text { shortcomings. }\end{array}$ \\
\hline
\end{tabular}

In clinical practice, we frequently encounter patients who are unable to break off deeply destructive intimate relationships that cause them suffering and compromise their lives on various levels; this condition is classified as "affective dependence" [4-7] However, this behavioral expression is common to many personality disorders, such as dependent disorder [8], histrionic disorder [9], borderline disorder [10] and narcissistic disorder [11]. Indeed: in the dependent disorder, the main feature is precisely that of the toxic and destructive bond that reinforces one's personality tendency, as in a vicious circle; in the histrionic disorder, the affective dependence is functional to its tendency to dramatize, to try to capture the impression or attention of others, to continue to feed potentially useful situations to maintain its real or fictitious bond with the third party; in the hypothesis of borderline disorder, affective dependence is necessary to continue to maintain the bond with the person on levels of high instability, favoring first a morbid attachment and then a clear separation, alternating these behaviors in synchrony; finally, in narcissistic disorder the patient implements modes of affective dependence in the hypothesis of "covert" narcissism, that is, the form that provides low self-esteem and high sensitivity to criticism [1218].

\section{Perrotta Affective Dependence Questionnaire (PAD-Q)}

Starting from the concept of "affective dependence" and its international nosographic framework, the Perrotta Affective Dependence Questionnaire $(P A D-Q)$ aims to study the phenomenon of "affective dependence", defining it as a maladaptive model of the affective-sentimental relationship of a couple, which involves the establishment or persistence of a clinically significant bond, lasting at least six months and characterized by a functional impairment of the relational area, the emotional area and the somatic area.

In particular, the passive subject of the relationship, suffering from emotional dependence, experiences the following symptomatological picture:

a) "relational area": relational dependence/codependence, assumption of other people's responsibility with significant delegation, excessive justification of the partner's injurious, offensive or disparaging conduct, dynamics of psychophysical submission or subordinate relationship, excessive need for reassurance, attention or relational certainty, unfounded fear of abandonment.

b) "somatic area": malaise emotional, relational, affective, sentimental and physical, excessive tolerance in relation to episodes harmful, abusive or disparaging of the partner, masochistic dynamics.

c) "emotional area": inability to manage anxiety, low tolerance to frustration, emotional instability, need for control, unmotivated fears, low self-esteem, verbal and/ or physical denigration, obsessive and/or delusional episodes.

Affective addiction, not being a well-identified psychopathological label in the international nosographic framework, except in the general framework of behavioral addictions, in this context is identified as a maladaptive behavioral model that describes a series of personality traits afferent to several nosographically recognized psychopathological disorders. In particular, according to this excellent, the patient who will present to the proposed 
questionnaire the following total overall scores will receive the following diagnoses:

1) Behavior in the normal range: $0-35$.

2) Dysfunctional behavior: 36 - 50 .

3) Dysfunctional attitude: $51-65$.

4) Dysfunctional Inclination: $66-80$.

5) Dysfunctional predisposition: $81-95$.

6) Clinically relevant condition:

a. moderate level: 96 - 115,

b. significant level: 116 - 135,

c. severe level: $136-155$.

d. very severe level: $156-175$

On the basis of the summation of the individual categories it is possible to identify the pathological subtypes, provided that the overall total score is equal to or greater than $96 / 175$. The subtype that obtains the highest score represents the most representative type of the patient:

a) Type I: Affective neurotic: the person with the highest cumulative score in the type I items (items 10, 11, $13,19,22)$ describes him/herself with a tendency to frequently use neurotic defence mechanisms to obtain secondary benefits, preoccupation when having to meet the partner's expectations, brooding and disturbing fantasies related to the relationship, catastrophic ideas and negative and pessimistic ideations.

b) Type II: Dependent: the person with the highest cumulative score in the type II items (items 2, 3, 8, 25, 26) describes him/herself with a tendency to lose contact with his/her own emotions by putting his/her partner's needs and expectations first, seeking approval and reassurance from his/her partner, generalised anxiety, unfounded fear that his/her partner might prefer another person and the use of cognitive distortions and self-deception to justify his/her behaviour.

c) Type III: Histrionic: the person with the highest cumulative score in the type III items (items 15, 17, $18,21,24$ ) describes him/herself as having a tendency to fear stability in relationships (even though he/she seems to be looking for it very hard), theatricality in the manifestation of his/her emotions, dramatic and excessive reactions, looking for complex emotional situations or with complicated people and the use of complaining.

d) Type IV: Masochistic: the person with the highest cumulative score in the type IV items (items 1, 7, 14, 29, 30) describes him/herself with a tendency to excessively tolerate and justify his/her partner's behaviour, even if disrespectful or inadequate, excessive attention in the relationship and towards the romantic relationship with relative excessive emotional investment, putting his/her own rights and needs first and delegitimising actions in favour of the partner.

e) Type V: Borderline: the person with the highest cumulative score in the type $\mathrm{V}$ items (items 5, 6, 9, 12, 28) describes him/herself with a tendency to feel empty or bored, an impelling need for an affective, sentimental or sexual relationship even with people one has only just met, fear of abandonment and loneliness, use of idealisation/devaluation in the relationship.

f) Type VI: Covert Narcissist: the person with the highest cumulative score in the type VI items (items 4, 16, 20, 23, 27) describes him/herself as having a tendency to prefer complicated, troubled or dramatic relationships even if he/she declares him/herself to be unhappy, an unfounded fear that the partner does not love him/ her enough, a need to conquer people who initially show little interest or disinterest, passive-aggressive manipulation of the relationship and difficulty in maintaining distance and boundaries with the partner.

g) Type VII: Psychotic: the person with the highest cumulative score in the type VII items (items 31, 32, 33, 34, 35) describes him/herself as having a solitary tendency, a preference for closure, a very controlled emotionality, frequent masturbatory activity with limited sexual intercourse in pairs, obsessions, delusions and an excessive concentration on the partner's pleasure as a priority to the detriment of his/ her own body and needs.

The completion of the questionnaire must be done by the therapist, after the drafting of the previous history [19-23] and clinical interview and serves to better define the general framework based on the symptoms reported and possibly found, which can range from neurotic to bordeline and psychotic [24-52].

The above psychopathological types do not recall any international nosographics of mental disorders equally named but simply recall, by personality traits, such disorders, which to be diagnosed in their complexity need further psychometric investigations; complexity that can also be studied through the newly proposed PICI-1 model [53-56].

Following the clinical interview, the therapist initials the responses of each item, entering a value from 0 to 5 where 5 equals "absolutely agree" and o equals "not at all agree." Once the answers have been initialed, the therapist proceeds to the summation of the results, obtaining any relevant values, initialing the groups of items of the psychopathological subtypes only if the final summation gives a result equal to or greater than $96 / 175$.

The complete questionnaire is attached to this research.

Citation: Perrotta G (2021) Perrotta Affective Dependence Questionnaire (PAD-Q): Clinical framing of the affective-sentimental relational maladaptive model. Ann Psychiatry Treatm 5(1): 062-066. DOI: https://dx.doi.org/10.17352/apt.000032 


\section{Conclusion}

The Perrotta Affective Dependence Questionnaire (PAD-Q), with 35 items, on a $0-5$ scale, aims to study the phenomenon of "affective dependence", defining it instead as a maladaptive model of the affective-sentimental relationship of a couple, which involves the establishment or persistence of a clinically significant bond, lasting at least six months and characterized by a functional impairment of the relational area, the emotional area and the somatic area. In this sense, the questionnaire proposes an investigation more closely related to personality traits, thus favoring a more complex and articulated approach, aimed at clinical treatment, in a framework of diagnostic transversality, to the best possible therapy, always integrated between psychopharmacology and psychotherapy [57,58], departing from the simple nosographic classification of behavioral addiction.

\section{(Appendix)}

\section{References}

1. Perrotta G (2020) Affective Dependence: from pathological affectivity to personality disorders. Definitions, clinical contexts, neurobiological profiles and clinical treatments. Health Sci 1: 1-7. Link: https://bit.ly/2TXmTdj

2. Reynaud $M$, Karila L, Blecha L, Benyamina $A(2010)$ Is love passion an addictive disorder? Am J Drug Alcohol Abuse 36: 261-267. Link: https://bit.ly/3xzOAJD

3. Millon T, Millon CM, Meagher SE, Grossman SD, Ramnath R (2004) Personality disorders in modern life. Wiley. Link: https://bit.ly/3qYikvw

4. APA (2013) DSM-V, Diagnostic and Statistical Manual of Mental Disorders, Fifth Ed.

5. Perrotta G (2019) Psicologia generale. Luxco Ed, 1th ed.

6. Perrotta G (2019) Psicologia dinamica. Luxco Ed, 1th ed.

7. Perrotta G (2019) Psicologia clinica. Luxco Ed, 1th ed.

8. Perrotta G (2020) Affective Dependence: from pathological affectivity to personality disorders. Definitions, clinical contexts, neurobiological profiles and clinical treatments. Health Sci 1: 1-7. Link: https://bit.ly/2TXmTdj

9. Perrotta G (2021) Histrionic personality disorder: Definition, clinical profiles, differential diagnosis and therapeutic framework. Arch Community Med Public Health 7: 001-005. Link: https://bit.ly/3cugaOH

10. Perrotta G (2020) Borderline Personality Disorder: definition, differential diagnosis, clinical contexts and therapeutic approaches. Ann Psychiatry Treatm 4: 043-056. Link: https://bit.ly/3hx2B1N

11. Perrotta G (2020) Narcissism and psychopathological profiles: definitions, clinical contexts, neurobiological aspects and clinical treatments. J Clin Cases Rep 4: 12-25.

12. Fisher HE, Xu X, Aron A, Brown LL (2016) Intense, passionate, romantic love: a natural addiction? How the fields that investigate romance and substance abuse can inform each other. Front Psychol 7: 687. Link: https://bit.ly/3hRUSfn

13. Stanley SA (2017) Addicted to Love? Sci Transl Med 9. Link: https://bit.ly/3e5aWJv

14. Gratz KL, Roemer L (2004) Multidimensional Assessment of Emotion Regulation and Dysregulation: Development, Factor Structure, and Initial Validation of the Difficulties in Emotion Regulation Scale. Journal of Psychopathology and Behavioral Assessment 26: 41-54. Link: https://bit.ly/2T5ddxc
15. Cermak T (1986) Diagnosing and Treating Co-dependence. Johnson Books, Minnesota.

16. Kernberg OF (1995) Relazioni d'amore: normalità e patologia. Cortina, Milano.

17. Earp BD, Wudarczyk OA, Foddy B, Savulescu J (2017) Addicted to love: what is love addiction and when should it be treated? Philos Psychiatr Psychol 24: 77-92. Link: https://bit.ly/3hsn9tz

18. Zou Z, Song $H$, Zhang $Y$, Zhang $X$ (2016) Romantic love vs. drug addiction may inspire a new treatment for addiction. Front Psychol 7: 1436. Link: https://bit.ly/3rcK1B7

19. Perrotta G (2019) The reality plan and the subjective construction of one's perception: the strategic theoretical model among sensations, perceptions, defence mechanisms, needs, personal constructs, beliefs system, social influences and systematic errors. J Clinical Research and Reports 1. Link: Link: https://bit.ly/3b34baH

20. Perrotta G (2020) Psychological trauma: definition, clinical contexts, neural correlations and therapeutic approaches. Curr Res Psychiatry Brain Disord: CRPBD-100006. Link: https://bit.ly/37UD3bz

21. Perrotta G (2020) Human mechanisms of psychological defence: definition, historical and psychodynamic contexts, classifications and clinical profiles. Int J Neurorehabilitation Eng 7: 1. Link: https://bit.ly/2L015dJ

22. Perrotta G (2020) Dysfunctional attachment and psychopathological outcomes in childhood and adulthood. Open J Trauma 4: 012-021. Link: https://bit.ly/2Mi2ThB

23. Perrotta G (2020) Neonatal and infantile abuse in a family setting. Open $J$ Pediatr Child Health 5: 034-042. Link: https://bit.ly/2KApVQo

24. Perrotta G (2019) Anxiety disorders: definitions, contexts, neural correlates and strategic therapy. J Neur Neurosci 6: 046. Link: https://bit.ly/2WSmiaT

25. Perrotta G (2019) Neural correlates in eating disorders: Definition, contexts and clinical strategies. J Pub Health Catalog 2: 137-148. Link: https://bit.ly/3mWmf8s

26. Perrotta G (2019) Post-traumatic stress disorder: Definition, contexts, neural correlations and cognitive-behavioral therapy. J Pub Health Catalog 2: 40-47. Link: https://bit.ly/3rvaCc6

27. Perrotta G (2019) Sleep-wake disorders: Definition, contexts and neural correlations. J Neurol Psychol 7: 09. Link: https://bit.ly/3hoBiGO

28. Perrotta G (2019) Depressive disorders: Definitions, contexts, differential diagnosis, neural correlates and clinical strategies. Arch Depress Anxiety 5: 009-033. Link: https://bit.ly/2KADvDm

29. Perrotta G (2019) Panic disorder: definitions, contexts, neural correlates and clinical strategies. Current Trends in Clinical \& Medical Sciences 1. Link: https://bit.ly/38IG6D5

30. Perrotta G (2019) Obsessive-Compulsive Disorder: definition, contexts, neural correlates and clinical strategies. Cientific Journal of Neurology 1: 08-16. Link: https://bit.ly/3pxNbNu

31. Perrotta G (2019) Behavioral addiction disorder: definition, classifications, clinical contexts, neural correlates and clinical strategies. J Addi Adol Beh 2. Link: https://bit.ly/3rAT9ip

32. Perrotta G (2019) Delusions, paranoia and hallucinations: definitions, differences, clinical contexts and therapeutic approaches. Cientific Journal of Neurology (CJNE) 1: 22-28. Link: https://bit.ly/3ht2nKz

33. Perrotta $G$ (2019) The acceptance in the elaboration of mourning in oncological diseases: definition, theoretical models, and practical applications. Needs analysis and subjective oncological reality. Biomed J Sci Tech Res 21. Link: https://bit.ly/3htWrBa 
34. Perrotta G (2019) Paraphilic disorder: definition, contexts and clinical strategies. J Neuro Research 1: 4. Link: https://bit.ly/3gxr1t3

35. Perrotta G (2019) Internet gaming disorder in young people and adolescent: a narrative review. J Addi Adol Beh 2. Link: https://bit.ly/3rTbAyZ

36. Perrotta G (2019) Bipolar disorder: definition, differential diagnosis, clinical contexts and therapeutic approaches. J Neuroscience and Neurological Surgery 5. Link: https://bit.ly/34SoC67

37. Perrotta G (2020) Suicidal risk: definition, contexts, differential diagnosis, neural correlates and clinical strategies. J Neuroscience Neurological Surgery 6: 114. Link: https://bit.ly/3aMqcu5

38. Perrotta G (2020) Pedophilia: definition, classifications, criminological and neurobiological profiles and clinical treatments. A complete review. Open J Pediatr Child Health 5: 019-026. Link: https://bit.ly/38Jzggz

39. Perrotta G (2020) Gender dysphoria: definitions, classifications, neurobiological profiles and clinical treatments. Int J Sex Reprod Health Care 3: 042-050. Link: https://bit.ly/3vssyFf

40. Perrotta G (2020) Apraxia: definition, clinical contexts, neurobiological profiles and clinical treatments. Global J Medical Clin Case Rep 7: 059-061. Link: https://bit.ly/3wwsiFx

41. Perrotta G (2020) Agnosia: definition, clinical contexts, neurobiological profiles and clinical treatments. Arch Gerontol Geriatr Res 5: 031-035. Link: https://bit.ly/3r2owm5

42. Perrotta G (2020) Dysarthria: definition, clinical contexts, neurobiological profiles and clinical treatments. Arch Community Med Public Health 6: 142 145. Link: https://bit.ly/3hqRiK5

43. Perrotta G (2020) Epilepsy: from pediatric to adulthood. Definition, classifications, neurobiological profiles and clinical treatments. J Neurol Neurol Sci Disord 6: 014-029. Link: https://bit.ly/3vz3ltv

44. Perrotta G (2020) The concept of altered perception in "body dysmorphic disorder": the subtle border between the abuse of selfies in social networks and cosmetic surgery, between socially accepted dysfunctionality and the pathological condition. J Neurol Neurol Sci Disord 6: 001-007. Link: https://bit.ly/3wffHXp

45. Perrotta G (2020) Sexual orientations: a critical review of psychological, clinical and neurobiological profiles. Clinical hypothesis of homosexual and bisexual positions. Int $\mathrm{J}$ Sex Reprod Health Care 3: 027-041. Link: https://bit.ly/38DtEVa

46. Perrotta G (2020) Cuckolding and Troilism: definitions, relational and clinical contexts, emotional and sexual aspects and neurobiological profiles. A complete review and investigation into the borderline forms of the relationship: Open Couples, Polygamy, Polyamory. Annals of Psychiatry and Treatment Ann Psychiatry Treatm 4: 037-042. Link: https://bit.ly/2TFODD3

47. Perrotta G (2020) Agraphia: definition, clinical contexts, neurobiologica profiles and clinical treatments. Journal of Neuroscience and Neurological Surgery 6. Link: https://bit.ly/3wwxvNR

48. Perrotta G (2020) The pharmacological treatment of epileptic seizures in children and adults: introduction, clinical contexts, psychopharmacological profiles and prospects in the neurogenetic field. Journal of Neuroscience and Neurological Surgery 6: 8. Link: https://bit.ly/3g3hRmV

49. Perrotta G (2020) Aphasia: definition, clinical contexts, neurobiological profiles and clinical treatments. Ann Alz Dement Care 4: 6. Link: https://bit.ly/3xw6Py3
50. Perrotta G (2020) Dysfunctional sexual behaviors: definition, clinical contexts neurobiological profiles and treatments. Int J Sex Reprod Health Care 3: 061 069. Link: https://bit.ly/3hxT4aU

51. Perrotta G (2020) Bisexuality: definition, humanistic profiles, neural correlates and clinical hypotheses. J Neuroscience and Neurological Surgery 6. Link: https://bit.ly/2L6VXmA

52. Perrotta G (2021) Maladaptive stress: Theoretical, neurobiological and clinical profiles. Arch Depress Anxiety 7: 001-007. Link: https://bit.ly/3sDs39Y

53. Perrotta G (2020) Perrotta Integrative Clinical Interview, LK 270.

54. Perrotta G (2020) The structural and functional concepts of personality: The new Integrative Psychodynamic Model (IPM), the new Psychodiagnostic Investigation Model (PIM) and the two clinical interviews for the analysis of personality disorders (Perrotta Integrative Clinical Interview or PICI) for adults and teenagers (1TA version) and children (1C version), Psychiatry Peertechz, E-book. Link: https://bit.ly/2SqQevV

55. Perrotta G (2020) First revision of the Psychodiagnostic Investigation Mode (PIM-1R) and elaboration proposal of a clinical interview for the analysis of personality disorders (Perrotta Integrative Clinical Interview or $\mathrm{PICl}$ 1) for adults, teenagers and children. Psychiatry Peertechz, E-book. Link: https://bit.ly/2MQe3dY

56. Perrotta G (2020) "Perrotta Integrative Clinical Interview (PICl-1)" Psychodiagnostic evidence and clinical profiles in relation to the MMPI-II, Ann Psychiatry Treatm 4: 062-069. Link: https://bit.ly/3q0bYLP

57. Perrotta G (2020) The strategic clinical model in psychotherapy: theoretical and practical profiles. J Addi Adol Behav 3: 5. Link: https://bit.ly/3aPMx9X

58. Perrotta G (2020) Accepting "change" in psychotherapy: from consciousness to awareness. Journal of Addiction Research and Adolescent Behaviour 3.

\section{Discover a bigger Impact and Visibility of your article publication with}

\section{Peertechz Publications}

\section{Highlights}

* Signatory publisher of ORCID

* Signatory Publisher of DORA (San Francisco Declaration on Research Assessment)

- Articles archived in worlds' renowned service providers such as Portico, CNKI, AGRIS, TDNet, Base (Bielefeld University Library), CrossRef, Scilit, J-Gate etc.

* Journals indexed in ICMJE, SHERPA/ROMEO, Google Scholar etc.

* OAI-PMH (Open Archives Initiative Protocol for Metadata Harvesting)

* Dedicated Editorial Board for every journal

* Accurate and rapid peer-review process

* Increased citations of published articles through promotions

* Reduced timeline for article publication

Submit your articles and experience a new surge in publication services (https://www.peertechz.com/submission).

Copyright: ( 2021 Perrotta G. This is an open-access article distributed under the terms of the Creative Commons Attribution License, which permits unrestricted use distribution, and reproduction in any medium, provided the original author and source are credited.

Citation: Perrotta G (2021) Perrotta Affective Dependence Questionnaire (PAD-Q): Clinical framing of the affective-sentimental relational maladaptive model. Ann Psychiatry Treatm 5(1): 062-066. DOI: https://dx.doi.org/10.17352/apt.000032 